\title{
Saliva: control nervioso, composición y función
}

\author{
Saliva: nervous control, composition and function
}

Saliva: controle nervoso, composição e função

\begin{abstract}
Regis André Ticona-Vidal ${ }^{1 a}$
Luis Fernando Maquera-Quispe ${ }^{1 a}$

Deysi Marianella Tuyo-Aduviri ${ }^{1 a}$

Larissa Xiomara Huiza-Cutipa $^{19}$

Paola Pierina Barreda-Palacios ${ }^{1 a}$

Esperanza Evelyn Ramirez-Alanoca ${ }^{1 a}$

Alejandro Javier Mamani-Barrueta ${ }^{19}$

Rubí Eliam Velarde-Quispe ${ }^{1 a}$

Anthony Alvaro Velarde-Quispe ${ }^{1 a}$
\end{abstract}

(iD) https://orcid.org/0000-0003-0744-2031
(iD https://orcid.org/0000-0002-0117-6484
(iD https://orcid.org/0000-0001-9068-7480
(iD https://orcid.org/0000-0001-9973-7747
(iD https://orcid.org/0000-0001-8621-1826
(iD https://orcid.org/0000-0003-2609-8416
(iD https://orcid.org/0000-0003-2672-6101
(iD https://orcid.org/0000-0002-7614-7039
(iD https://orcid.org/0000-0002-3272-8341

\section{Resumen}

El control nervioso de la secreción salival es exclusivo del sistema nervioso autónomo, el cual tiene una parte simpática, que se origina de segmentos torácicos; y una parasimpática, que se da por medio de señales nerviosas provenientes de los núcleos salivales. El control nervioso inicia al estar frente a estímulos gustativos, que es mediado por el NCV3 (tercera rama del nervio trigémino), el NC VII (nervio facial) y el NCIX (nervio glosofaríngeo). Además, el recorrido que sigue la estimulación para la secreción salival es: fibras preganglionares $\rightarrow$ ganglio $\rightarrow$ fibras posganglionares parasimpáticas. La saliva está compuesta por un 95 a $99 \%$ de agua y el porcentaje restante corresponde a los sólidos que se subdividen en orgánicos, donde se encuentran compuestos proteicos como enzimas e inmunoglobulinas; no proteicos como la urea e inorgánicos que se comportan como electrolitos. Asimismo, por su composición cumple funciones tanto alimentarias como relacionadas a la salud bucal y a la fonación. de la saliva

Palabras clave: control nervioso de la secreción salival, composición salival, secreción salival, funciones

\section{Abstract}

The nervous control of salivary secretion is exclusive to the autonomic nervous system, which has a sympathetic part, which originates from the thoracic segments; and a parasympathetic, which occurs through nerve signals from the salivary nuclei. Nerve control begins with gustatory stimuli, which are mediated by NCV3 (third branch of the trigeminal nerve), NC VII (facial nerve), and NCIX (glosopharyngeal nerve). In addition, the pathway that follows the stimulation for salivary secretion is: preganglionary fibers, ganglion, and fibers postanglionary parasympathetic fibers. Saliva is composed of 95 to $99 \%$ water and the remaining percentage corresponds to solids that are subdivided into organic, where protein compounds such as enzymes and immunoglobulins are found; non-protein such as urea and inorganic compounds that behave as electrolytes. In addition, due to its composition, it fulfils functions related to oral health and phonation.

Keywords: nerve control of salivary secretion, salivary composition, salivary secretion, salivary functions

\footnotetext{
${ }^{1}$ Universidad Nacional Jorge Basadre Grohmann. Tacna, Perú

${ }^{a}$ Estudiante de la Escuela de Medicina Humana
} 


\section{Resumo}

O controle nervoso da secreção salivar é exclusivo do sistema nervoso autônomo, que tem uma parte simpática, que se origina de segmentos torácicos; e uma parassimpático, que se dá por meio de sinais nervosos provenientes dos núcleos salivares. O controle nervoso inicia-se ao estar frente a estímulos gustativos, que é mediado pelo NCV3 (terceiro ramo do nervo trigêmeo), o NC VII (nervo facial) e o NCIX (nervo glosofaríngeo). Além disso, o percurso que segue a estimulação para a secreção salivar é: fibras preganglionares gânglios fibras posganglionares parasimpáticas. A saliva é composta por 95 a 99 \% de água e a porcentagem restante corresponde aos sólidos que se subdividem em orgânicos, onde se encontram compostos proteicos como enzimas e imunoglobulinas; não proteicos como a ureia e inorgânicos que se comportam como eletrólitos. Além disso, pela sua composição cumpre funções tanto alimentares como relacionadas à saúde bucal e à fonação.

Palavras-chave: control nervoso da secreção salival, composição salival, secreção salival, funções da saliva

\section{Introducción}

El estudio de la saliva ha sido tema de investigación que ha ido creciendo en las últimas 2 décadas, con mayor relación en el diagnóstico de enfermedades, por lo que la presente revisión bibliográfica se enfoca en el estudio del control nervioso en la secreción salival, además de su composición y funciones.

La saliva es un fluido biológico viscoso que humedece la cavidad bucal, la cual es secretada por todas las glándulas salivales mayores y menores. ${ }^{1}$ Es estéril cuando sale de las glándulas salivales, pero deja de serlo inmediatamente cuando se mezcla con el fluido crevicular, restos alimenticios, microorganismos y células descamadas de la mucosa oral, ${ }^{2}$ que le otorgan un $\mathrm{pH}$ ácido que oscila entre 6 a 7.

Su control nervioso es mediado por el sistema nervioso autónomo, por un lado, la regulación parasimpática (NC V3, NC VII y el NC IX) a través de señales nerviosas provenientes de los núcleos salivales superior e inferior del tronco encefálico (entre el bulbo raquídeo y el puente de varolio); ${ }^{3}$ y por el otro, la regulación simpática que se originan en los segmentos torácicos T1 a T3 con nervios preganglionares que establecen sinapsis en el ganglio cervical superior. ${ }^{4}$

Está compuesta por agua, proteínas como la amilasa salival, la mucina, lisozima, factores de crecimiento nervioso y epidérmico; enzimas como la catalasa e inmunoglobulinas como IgA, IgM, IgG. Dentro de sus componentes no proteicos tenemos a la urea y creatinina. Por otro lado, en su composición inorgánica encontramos a iones que se comportan como electrolitos. ${ }^{2,5,6}$

La saliva cumple funciones a nivel bucal como la degradación de alimentos, formación del bolo alimenticio, capacidad amortiguadora, aclaramiento salival, remineralización, antibacterial, reparación del tejido bucal, formación de la placa microbiana adquirida y la articulación de las palabras. ${ }^{2}$

El objetivo de esta revisión fue profundizar en el control simpático y parasimpático de la saliva, precisar la composición de la saliva e identificar las funciones de la saliva.

\section{Método}

Se realizó una revisión bibliográfica sobre el control nervioso, funciones y composición de la saliva en agosto del 2020. Se evaluaron artículos y libros publicados en los últimos 10 años, tanto en idioma inglés como en español. Como resultado de la búsqueda se obtuvieron 19 fuentes de información, que fueron tamizadas con el propósito de conservar solo las que describieron mejor los elementos de la revisión; de esta manera, el estudio se circunscribe a solo 15 . Para el procesamiento 
de la información se elaboró un documento de recolección de información, a través de Microsoft Word 2019 y finalmente en base a este se confeccionó un documento que agrupó todas las fuentes.

\section{Resultados}

\section{bucal}

\section{Control nervioso de la secreción}

La salivación, que en promedio es de $1000 \mathrm{ml}$ por día, tiene dos características inusuales en su regulación: su control es exclusivo del sistema nervioso autónomo ${ }^{3}$ y está inervado por el sistema nervioso simpático y parasimpático aumentando así la secreción salival. Esta salivación se da con un mayor predominio parasimpático. ${ }^{4}$

a) Control parasimpático: "La secreción salival es desencadenada por las impresiones olfativas y gustativas, además de un cierto orden psíquico, que son comunicadas al núcleo salivar superior, situado en la protuberancia y en el núcleo salivar inferior, que se halla en el bulbo raquídeo."7

- Estimulación parasimpática: La secreción de la saliva se da por estímulos gustativos, como sabores amargos en la lengua o estímulos táctiles, como la presencia de objetos lisos en la boca, además de centros superiores del sistema nervioso central como el área del apetito. Gracias a esto se mantienen húmedas las mucosas y se lubrica la lengua y los labios durante el habla. Cabe recalcar que la estimulación disminuye con el miedo, el sueño y la deshidratación. ${ }^{3}$

- Vías motoras: "Las aferencias parasimpáticas hacia las glándulas salivales son transportadas por los nervios facial y glosofaríngeo". ${ }^{4}$ Las fibras preganglionares del núcleo salival superior son vehiculizadas por el nervio facial y pasan por intermedio de la cuerda del tímpano al nervio lingual. Éste las lleva al ganglio submandibular, donde hacen sinapsis con las neuronas posganglionares parasimpáticas. Los axones que salen del ganglio se distribuyen en las glándulas submandibulares y sublinguales. Las fibras preganglionares del núcleo salival inferior son vehiculizadas por el nervio glosofaríngeo. A través de su ramo, el nervio timpánico, se forma el plexo timpánico, de donde sale el nervio petroso menor, que se dirige al ganglio ótico. De éste salen las fibras posganglionares parasimpáticas, que van por el nervio auriculotemporal hacia la parótida." "Las neuronas parasimpáticas posganglionares liberan acetilcolina (ACh), que interacciona con los receptores muscarínicos de las células acinares y ductales, provocando la secreción de saliva". ${ }^{4}$

b) Control simpático: Aunque su estimulación incrementa la salivación, es mucho menor que la parasimpática y a diferencia de esta, predomina durante el estrés y causa la sequedad bucal.

- Estimulación simpática: Algunos estudios en humanos y ratas han demostrado que los impulsos simpáticos contribuyen a la cantidad de proteína secretada bajo la estimulación refleja del gusto. ${ }^{8}$

- Vías motoras: "Las aferencias simpáticas que llegan a las glándulas salivales se originan en los segmentos torácicos T1 a T3 con nervios preganglionares que establecen sinapsis en el ganglio cervical superior. Las posganglionares liberan noradrenalina que interacciona con los receptores betaadrenérgicos, lo que da lugar a la estimulación de la adenilil ciclasas y producción de monofosfato cíclico de adenosina (AMPc), esta última aumenta la salivación". ${ }^{3}$

Para poder explicar gráficamente el control nervioso de la secreción salival mediada por nervios, se anexó una imagen que fue extraída de la revista Periodontology 2000 . EI reflejo salival comienza con la detección de alimentos y saborizantes, a través de las papilas gustativas y los mecanorreceptores en la lengua. Las señales de los nervios sensoriales aferentes (verde) se transmiten a los centros salivales desde donde se encuentran los nervios parasimpáticos eferentes (azules), los cuales conducen señales a las glándulas salivales. Los nervios eferentes simpáticos (rojos) surgen de la médula espinal torácica. Los nervios dentro del sistema nervioso central (negro) inervan a los 
centros salivales y a las influencias nerviosas mediadas por señales nerviosas a las glándulas salivales. $^{8}$

\section{Estimulación nerviosa de la secreción salival}

En la inervación de las glándulas salivales y conducción del impulso nervioso intervienen principalmente el glosofaríngeo, facial y tercera rama del nervio trigémino (mandibular).

El nervio glosofaríngeo es el responsable de la secreción parotídea; sus fibras siguen la vía incluida en el trigémino a través del nervio auriculotemporal. ${ }^{9}$

"(...) el facial controla, gracias al trigémino, que conduce sus fibras vegetativas al territorio terminal, las secreciones lagrimal, nasal y salival de las glándulas submandibulares y sublingual". ${ }^{9}$

El nervio mandibular, rama del trigémino, conduce las fibras vegetativas de las glándulas salivales para la parótida (prestadas del glosofaríngeo) y para las glándulas submandibular y sublingual (prestadas del sistema secretor del facial). ${ }^{9}$

\section{Composición de la saliva}

Las glándulas mayores y menores secretan este líquido insípido, inodoro, incoloro y viscoso. ${ }^{1,10}$ El cual contiene entre un 95 a $99 \%$ de agua y el porcentaje restante corresponden a sólidos orgánicos e inorgánicos. ${ }^{10}$

\section{a) Composición orgánica}

Proteica: Grupo compuesto por las enzimas que actúan ante cuadros inflamatorios y en la digestión, como la amilasa salival. En menor cantidad están la catalasa, anhidrasa carbónica secretora, desoxirribonucleasa, calicreína salival, fosfatasa alcalina, esterasa leucocitaria y lactoperoxidasa. Existe también la presencia de inmunoglobulinas como la lgA secretora $(\operatorname{slg} A)$, las cuales son la primera línea de defensa ante la presencia de agentes patógenos; glucoproteínas como la mucina encargada del propio aspecto viscoso y proteínas propiamente dichas como la cistatina, la estaterina, la prolina, la lisozima y la albúmina con acción a favor y en contra del huésped. Estas últimas encontradas en menor concentración a comparación de los compuestos mencionados anteriormente, siendo evidencia de la contribución pasiva del suero plasmático a la formación de la saliva; pero no significa que la saliva sea un filtrado del plasma; por el contrario, es un cambio de un medio isotónico a uno hipotónico. ${ }^{2,11,5,6}$

No proteica: A diferencia de los componentes proteicos estos son productos terminales del metabolismo de las proteínas como el caso de la urea y la creatinina. Sin embargo, otros participan en el mantenimiento del equilibrio dentro de la cavidad oral como el amoníaco, el citrato y la glucosa. ${ }^{2}$

\section{b) Composición inorgánica}

La saliva final, además, está formada por componentes inorgánicos principalmente $\mathrm{Na}^{+}, \mathrm{Cl}^{-}, \mathrm{HCO}^{3-}$ y K $\mathrm{K}^{+}$, y en menor medida por $\mathrm{Ca}^{2+}, \mathrm{Mg}^{2+} \mathrm{y}$ fosfato quienes contribuyen con la osmolaridad, encontrándose en forma iónica o no iónica. ${ }^{12,2,6}$

A pesar de que la saliva este compuesta por múltiples elementos que generalmente están en pequeñas cantidades, se la debe considerar como un todo que es mayor que la suma de sus partes, ${ }^{5}$ variando su cantidad por los cambios de flujo, ritmo circadiano, tipo y tamaño de la glándula salival, duración y tipo de estímulo, dieta, drogas, edad, sexo o estado fisiológico; ${ }^{13}$ es decir que, en cada persona la función y concentración de cada componente varía.

\section{Funciones de la saliva}

Según Zaragoza y Molina, las funciones de la saliva se pueden clasificar en:

\section{a) Funciones alimentarias}

La secreción de la saliva comienza con la estimulación generada por los sentidos preparando a la cavidad bucal para poder recibir el alimento. ${ }^{6}$

Degradación de alimentos: La saliva al estar compuesta por enzimas, inicia el proceso digestivo en la cavidad oral a través de la amilasa salival, ${ }^{2}$ que degrada el almidón para formar hidratos de carbono y la lipasa, que se encarga de las grasas, continuando su función hasta el estómago. 
Formación del bolo alimenticio: La saliva al estar compuesta por un gran porcentaje de agua, ayuda a la mecánica de la masticación, formando de esa manera el bolo alimenticio donde también participan las glicoproteínas ricas en prolina. Por otro lado, la mucina que por su viscosidad unifica el bolo alimenticio y le otorga esa suavidad lo que facilita la deglución del mismo. ${ }^{2,6}$

Facilitar el sentido del gusto: Facilita el sabor y la detección de alimentos nutritivos. ${ }^{14}$

\section{bucal}

b) Funciones relacionadas a la salud

Van dirigidas al mantenimiento $y$ protección de las funciones en las estructuras de la cavidad bucal. ${ }^{6}$

Capacidad amortiguadora: Se da por la presencia de iones bicarbonato y fosfato cuando el flujo salival aumenta o disminuye. Ambos contrarrestan los cambios bruscos de $\mathrm{pH}$ en la cavidad oral, protegiendo a los tejidos orales de los ácidos provenientes de la comida - la placa dental reduciendo el potencial cariogénico que existe en el ambiente. Otro amortiguador destacable es la urea que es un residuo cargado negativamente de las proteínas que causa un aumento en el $\mathrm{pH}$ de la biopelícula mediante la liberación de amoniaco y dióxido de carbono cuando se hidroliza por ureasas bacterianas. $^{2}$

Aclaramiento salival: Es uno de los roles más importantes de la saliva, pues se trata de la eliminación de una sustancia presente en la saliva en un tiempo determinado; en otras palabras, es la dilución de los substratos bacterianos y azúcares ingeridos, ${ }^{2}$ disminuyendo la probabilidad de contraer lesiones cariosas.

Remineralización: Cuando los dientes hacen erupción, la saliva proporciona los minerales necesarios para completar su maduración gracias a que la hidroxiapatita de los dientes que está ligada al $\mathrm{pH}$ y a la saturación de iones de calcio y fosfato que también participan en la remineralización del esmalte siendo regulados por el citrato, las estatinas e histatinas. ${ }^{2,6}$

La presencia de fluoruro es decisiva ya que reducen la pérdida de mineral dental durante una disminución de $\mathrm{pH}^{2}$; además que, reduce la producción de ácidos en la placa microbiana.

Antibacterial: Parte de esta función es efectuada por la mucina y las glucoproteínas a base de prolina; que aparte de mantener húmeda la cavidad oral, protegen los tejidos orales contra los agentes irritantes y patógenos, ${ }^{5}$ pues ambos le proporcionan a la saliva una viscosidad en la cual quedan atrapados muchos microorganismos. Asimismo, las inmunoglobulinas son participes en esta función ya que actúan en la agregación bacteriana y previenen la adhesión de estos a los dientes.

Reparación de tejido: La presencia del factor de crecimiento epidérmico y nervioso aceleran el proceso de coagulación tras posibles heridas y erosiones, evitando que se produzca una penetración bacteriana. ${ }^{2,5,6}$

Formación de la placa microbiana adquirida: Así como la saliva ayuda a evitar la formación de bacterias, también es promotora de estas, debido a la antifuncionalidad de las proteínas que la conforman, en especial de aquellas ricas en prolina que pueden crear o influenciar en la formación de placas microbianas. ${ }^{13}$

\section{c) Función relacionada a la fonación}

Gracias a la lubricación originada por la mucina y las glucoproteínas a base de prolina, el movimiento de las estructuras de la cavidad bucal es continuo lo que hace posible la articulación de las palabras. ${ }^{6}$

\section{d) Función en odontología}

Ayuda al mantenimiento de una adecuada retención protésica, participando en los fenómenos físicos de adhesión, cohesión y tensión superficial. ${ }^{15}$ 


\section{Figura 1}

Control nervioso de la secreción salival

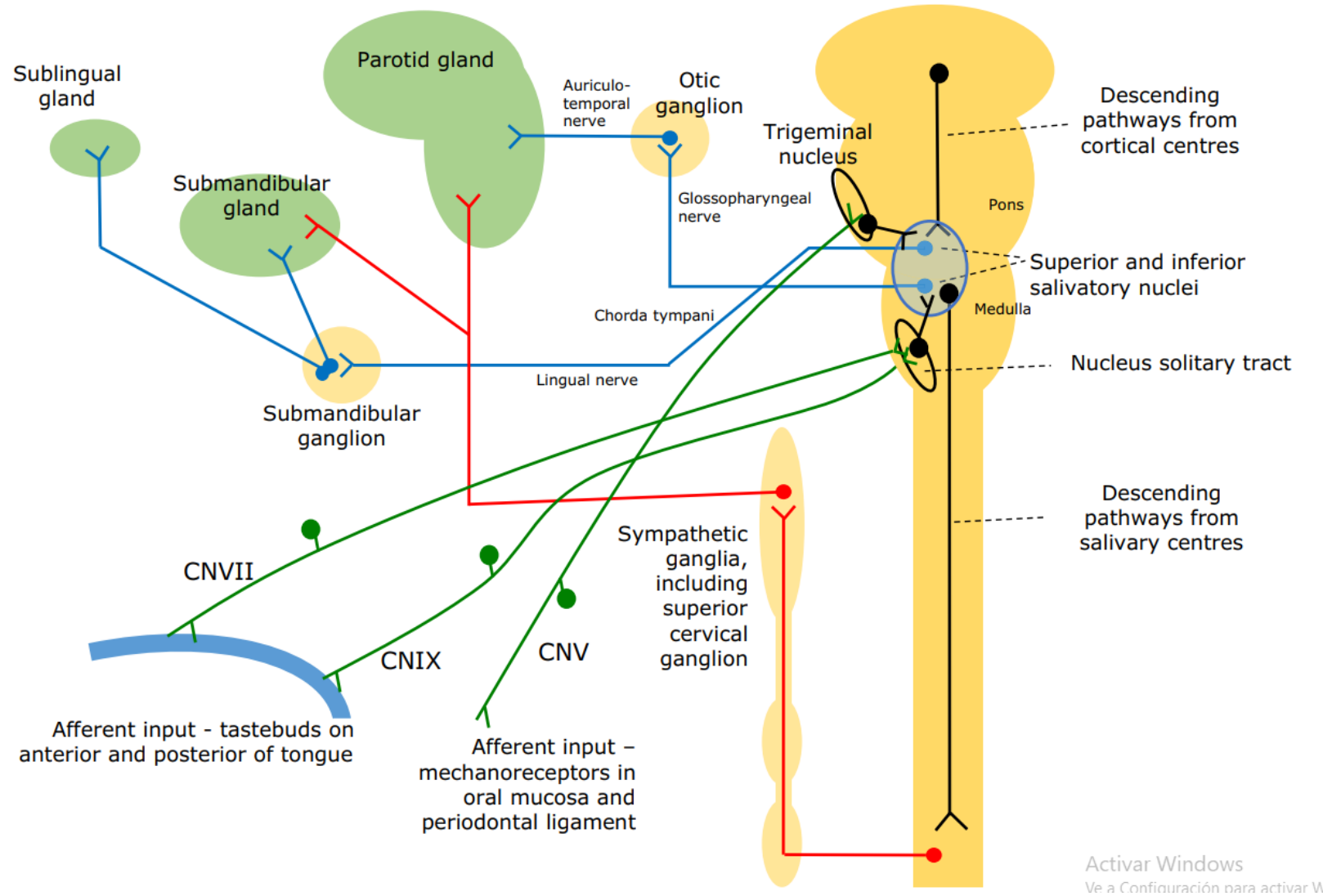

\section{Discusión}

Al iniciar la revisión, en libros sobre fisiología se encontraron similitudes entre Guyton y Costanzo, ambos indican que la salivación está controlada por señales nerviosas parasimpáticas y que un factor que también influye en las secreciones es el aporte sanguíneo. Entre las diferencias podemos mencionar que Guyton se centra en los estímulos parasimpáticos que pueden desencadenar la salivación; mientras que, Costanzo en la inervación fisiológica parasimpática y simpática. Anatómicamente, según Rouviere, el nervio glosofaríngeo, el nervio facial y la tercera rama del nervio trigémino (mandibular) son los principales actores responsables de la inervación de las glándulas salivales. Sin embargo, Latarjet define tanto al nervio facial como al glosofaríngeo como elementos de vehiculización de fibras preganglionares, incluyéndose en una secuencia nerviosa que va desde el núcleo salivar superior hasta la parótida.

Todos los artículos consultados presentan coincidencias referentes a la composición de la saliva; con la diferencia de que algunos de ellos exponen en su totalidad a los componentes, detallando el rol que cumplen como lo hace Zaragoza y Molina. Hernández; por otro lado, explica y precisa aquellos que considera importantes. A diferencia, Humphrey, Williamson y Sánchez los tratan de manera general, sin profundizar en cada uno de ellos. A pesar de las mínimas diferencias que presentan, estos artículos llegan a complementarse entre ellos, generando una información más íntegra.

Asimismo, se encontraron discrepancias con respecto a las funciones de la saliva; pues, cada autor propone una clasificación distinta. Según Zaragoza y Molina, 
las funciones de la saliva se dividen en tres grupos de manera general; por el contrario, Hernández describe de manera más explícita cada una de las funciones. Otros autores como Humphrey, Williamson y Sánchez organizan las funciones en cinco categorías; es decir que, no existe un modelo estándar que defina cómo se debe clasificar las funciones de la saliva.

El tema de esta revisión no precisa el estudio de la importancia que tiene la saliva en el diagnóstico médico, como se ve reflejado en los artículos, sino el estudio de los biomarcadores, que son componentes que la saliva proporciona, el cual es el tema que más interesa sobre este biolíquido.

Resulta importante mencionar que surgieron complicaciones a la hora de buscar información precisa sobre el tema, debido a que las fechas de publicación de artículos más afines a esta revisión eran desfasadas, por lo que hubo que hacer una búsqueda más exhaustiva. Asimismo, no se encontraron ejemplos de estímulos simpáticos en los libros, tan solo en un artículo donde se menciona superficialmente.

Aunque las fuentes consultadas albergan un volumen importante de información, probablemente exista información científica sobre los temas estudiados que no haya sido identificada en ellas.

\section{Conclusiones}

Al profundizar en el control simpático y parasimpático de la salivación pudimos entender la totalidad del mecanismo neurológico involucrado en este proceso, el cual es desencadenado por un estímulo ya sea gustativo, táctil, olfativo o visual, siendo uno de sus propósitos mantener la homeostasis.

Con la información recolectada se precisó que la saliva está compuesta por componentes inorgánicos y orgánicos como enzimas, inmunoglobulinas, urea, mucina, lisozima, etc. que se clasifican en proteicos y no proteicos los cuales son los responsables de su pHácido.

Se identificó que la saliva cumple una función alimentaria, antibacterial, amortiguadora, bacteriana, de remineralización y fonación que le conceden a este biolíquido una gran importancia en el organismo.

\section{Referencias}

1. Moore K, Dalley A, Agur A. Anatomía con orientación clínica. 8a edición. Buenos Aires: Wolters Kluwer; 2017.

2. Hernández A. Características y propiedades físico-químicas de la saliva: Una revisión. UstaSalud 2012; 11(2). http://revistas.ustabuca.edu.co/index.ph p/USTASALUD_ODONTOLOGIA/article/ view/1123/922 (último acceso 21 de agosto del 2020)

3. Hall J, Guyton A. Tratado de fisiología médica. 13a edición. Barcelona: Elsevier España; 2016. pág. 820.

4. Costanzo L. Fisiología. 5a edición. Barcelona: Elsevier España; 2014. pág 348-349.

5. Humphrey S., Williamson R. A review of saliva: Normal composition, flow, and function. The journal of prothestic d e n t is try $2010 ; 85(2)$. https://www.thejpd.org/article/S00223913(01)54032-9/fulltext (último acceso 21 de Agosto del 2020)

6. Zaragoza M., Molina J. La saliva, auxiliar de diagnóstico. México: FES Zaragoza; $\begin{array}{lllll}2 & 0 & 1 & 8\end{array}$. https://www.zaragoza.unam.mx/wpcontent/Portal2015/publicaciones/libros/ Saliva.pdf (último acceso 21 de agosto del 2020)

7. Latarjet M, Liard R. Anatomía Humana. Vol. Il. 4ta. Editorial Médica Panamericana. Argentina; 2005. Pág. 1275

8. Proctor GB. The physiology of salivary secretion. Periodontology 2000. 2016; 70(1):11-25.

9. Rouviere H. Anatomía Humana: Descriptiva, Topográfica y Funcional. Tomo I. 10. Editorial Masson.España; 2000. Págs. 246, 253, 257

10. Martina E, Campanati A, Diotallevi F, Offidani A. Saliva and Oral Diseases. Journal of Clinical Medicine [Internet]. 
MDPIAG; 2020 Feb 8; 9(2):466. Available from :

http://dx.doi.org/10.3390/jcm9020466

11. García Triana Bárbara E, Delfín Soto Olayo, Lavandero Espina Aleida M, Saldaña Bernabeu Alberto. Principales proteínas salivales: estructura, función y mecanismos de acción. Rev haban cienc méd [Internet]. 2012 Dic [citado 2021 Ene 31]; 11 (4): 450-456. Disponible en: http://scielo.sld.cu/scielo.php?script=sci a $r$ t e $x \mathrm{t} \& \mathrm{p}$ i d = S 1729 519X2012000400004\&Ing=es.

12. MESE, H., \& MATSUO, R. (2007). Salivary secretion, taste and hyposalivation. Journal of Oral Rehabilitation, 34(10), 711-723. doi:10.1111/j.1365-2842.2007.01794.x

13. Sánchez $P$. La saliva como fluido diagnóstico. SEQC 2013; 16:93-108. http://www.seqc.es/download/tema/7/33 24/346271904/840334/cms/tema-8-la$\mathrm{s}$ a l i v a $-\mathrm{c} \quad \mathrm{O} \mathrm{m} \quad \mathrm{o}$ fluidodiagnostico.pdf/\#: :text=COMPOSI CI\%C3\%93N\%20DE\%20LA\%20SALIVA , de $\% 20$ la $\% 20$ que $\% 20$ la $\% 20$ obtengamo s. (último acceso 21 de agosto del 2020)

14. Calatrava L. La saliva: Una ventana para el diagnóstico. Revista Venezolana de Investigación Odontológica IADR 2014; 2(2): 65-74. [citado 31 enero 2021]. D i s p o n i b 10 l e e n : http://revencyt.ula.ve/storage/repo/Archi voDocumento/rviodonto/v3n1/art07.pdf

15. Hovsepian Kepian M. La Función de la Saliva en la Retención de las Dentaduras Totales [Internet]. Red de repositorios Latinoamericanos. 2017 [citado 31 enero $\left.\begin{array}{llll}2 & 0 & 2 & 1\end{array}\right]$. D is pon ible en: https://repositorioslatinoamericanos.uchi le.cl/handle/2250/224442.

\section{Correspondencia:}

ajmamanib@unjbg.edu.pe
Fecha de recepción: 08/01/2021

Fecha de aceptación: 02/02/2021 